\title{
We welcome JPHP's new Editor-in-Chief: Elena N. Naumova
}

\author{
Anthony Robbins ${ }^{1} \cdot$ Phyllis Freeman ${ }^{2}$
}

Published online: 13 January 2020

(C) Springer Nature Limited 2019

It is with great pleasure we welcome a new Editor-in-Chief to the Journal of Public Health Policy. Elena Naumova will surely lead JPHP forward with imagination and rigor in an increasingly hazardous world. She has been our Statistical Editor since we took over JPHP in 2003, after Milton Terris, the founding Editor, died.

We thank the JPHP team at Palgrave/Springer currently led by Jessica Torr, and the search committee they engaged -3 members of the Editorial Board (James Chauvin-Canada, Peter Orris-United States, and Laetitia Rispel-South Africa) - who undertook a search over many months before selecting the new Editor. We thank all those who were willing to consider the JPHP editorship. We did not participate in the selection, thus our special thanks go to all those who did, on both sides of the search process-searchers and candidates.

And we want to add a special word about the many members of the team at Palgrave and Springer publishers who nurtured JPHP over the last 15 years: we have been incredibly well served by a long list of capable staff who devoted extra effort to help us meet JPHP goals, even when they may not have been entirely consistent with publishing 'business as usual.' And all have done so with notable generosity of spirit. We thank all of you-very much.

Let us tell you about Elena Naumova.

She is immensely accomplished. But, perhaps, what we have come to appreciate most over the last 15 years of working together on JPHP is that Elena never met a public health issue that failed to fascinate her. She has been a most enthusiastic, encouraging, and effective mentor for authors around the world, some of whom may never have realized all the potential in their data as they learned to with Elena's tutelage. She is brilliant in her own work and tireless in helping our authors to bring greater meaning to their work for JPHP's global readership. Many might never have succeeded in publishing their submissions but for her guidance and support.

Originally from Novosibirsk (Siberia), Russia, Elena studied mathematics and statistics there before moving to Japan, then the United States (US). First, she was at the

Phyllis Freeman

Phyllis.Freeman@umb.edu

1 Tufts University School of Medicine, Boston, MA, USA

2 University of Massachusetts Boston, Boston, MA, USA 
Center for Environmental Epidemiology, Medical College of Wisconsin, where she began her work in public health on issues related to air and water quality. Building from her mathematical foundation, she has since expanded the range of her public health focus to climate change, extreme weather, disease surveillance, immune response, and malnutrition. She is an avid advocate of using novel information technologies and underutilized data sources for public health research and practice.

In 1998, Elena moved to Tufts University's Department of Community Medicine and Public Health in the School of Medicine where we met in 2000 when Tony chaired that Department. She actively collaborated with many schools and departments, including the Sackler School of Graduate Biomedical Sciences Program, the Department of Mathematics in the College of Arts and Sciences, the School of Veterinary Sciences, and the School of Engineering before moving on to academic administrative responsibilities as Academic Dean for Faculty, Director of the Office of Faculty Affairs, and now as Chair of Nutrition Epidemiology and Data Sciences in the Friedman School of Nutrition Science and Policy.

She has authored more than 180 peer-reviewed articles and book chapters and worked with other public health journals in some editorial capacity. She is or has been Principal Investigator for millions of dollars of research grants from major science funders in the US, including many grants pertaining to climate change-and drawn considerable media attention to these topics. She has served on research review committees at the US federal agencies including the National Institutes of Health (NIH), the Environmental Protection Agency (EPA), the Centers for Disease Control and Prevention (CDC), and the National Science Foundation (NSF), and for foundation or governmental organizations in Canada, Kuwait, the Netherlands, Switzerland, and the United Kingdom. Her research has also taken her to work in Ecuador, Japan, India, Indonesia, Kenya, and Russia where she has close colleagues.

She has taught many courses, including Intermediate Biostatistics, Data Visualization, Advanced Data Analysis, and Environmental Informatics. The quality of attention she devotes to students has brought her large numbers of postdoctoral, doctoral, masters, and bachelor candidates with research projects for her to supervise. She cherishes the relationships built with her mentees and continues to collaborate and stay in touch with many of her students around the world.

In short, she is in great demand; we are honored that she has chosen to devote a substantial portion of her energy and intelligence to the Journal of Public Health Policy.

To edit a public health journal is a special challenge, as we have learned during our fifteen years at the JPHP. Health journals are numerous, but most of them are about medical services. In fact, public health is often assumed to mean government or public medical services. That is not our focus.

We think of public health as all activities that affect the health of the population: the environments where people carry on their personal and work lives and that produce the food, air, water, transportation systems, and services on which they depend; nutrition, climate, education, income, race, and poverty, and so on. JPHP's goal is to enlighten our readers about anything that enhances or damages the health of populations. We do not assume that medical services are the principal sources of improved population health. 
Under Elena's scientific leadership, we trust that $J P H P$ will continue to paint an informative picture of all the things that can harm or enhance health.

Anthony Robbins and Phyllis Freeman, Co-Editors. 